\title{
A Review Paper on Fabrication of Electric Power Operating Paper Cup Machine
}

\author{
Prof.S.S.Pawar ${ }^{1}$, Suraj P Dambhare ${ }^{2}$, Nikhil N Khekade ${ }^{3}$,Noman A khan ${ }^{4}$, Sanghadip N Raut ${ }^{5}$ \\ ${ }^{1}$ Associate Professor, ${ }^{2,3,4,5}$ UG Students \\ Department of Mechanical Engineering, Smt.Radhikataitai Pandav College of Engineering, Umred Road, Nagpur-441203
}

DOI: 10.46335/IJIES.2020.5.7.10

\begin{abstract}
Paper describes the development and design and fabrication electric power operating paper cup machine. The principle of operation of the machine is based on the movement of slider crank mechanism. After a short description of the basics of machine, this paper presents the analysis of the structure. The electric motor is operated paper cup making machine is to make the cup and fabricate the machine within minimum cost.
\end{abstract}

Keywords- Die and punch, Heater, motor, crank sliding mechanism, Electric motor.

\section{I- INTRODUCTION}

No ow In the day everyone needs less work but it is required high initial investment which is not possible to common man. So it has been try to make something that is affordable to common man and they can start their own business in their home with minimum investment. This proposal evaluates the technical feasibility and financial viability in setting up of a small -scale enterprise to do the activity on manufacturing and sale paper plate in small district and all over rural areas. Pedal power is the transfer of energy from a human source through the use of a foot pedal and crank system. As a consequence of the brainstorming exercise, it has been apparent that the primary function of pedal power one specific product is particularly useful. Disposable food packaging comprises disposable items often found in fast food restaurants, takeout restaurants and kiosks, and catering establishments. Food serving items for picnics and parties is very similar. Typical disposable foodservice products are plates, bowls, cups. These products can be made from a number of materials including plastics, paper, bio-resin and bamboo disposable foodservice packaging can be made from a number of materials each with its own uses and benefits. By reducing the need for equipment and additional labor, disposable foodservice packaging is an economical alternative to multiuse items and eliminates the need for dishwashers and other support equipment (racks, carts, dollies, shelving, bins) It can save money on water and energy used by dishwashers and can eliminates the need to replace reuse that are broken, damaged, stolen or accidentally discarded

\section{II-EXPERIMENTATION/FABRICATION}

For the fabrication of paper cup machine following types of equipment are used.

FRAME:- frame is used which is made from mild steel material in which frame is used for making paper cup by using punch and die. all the equipment are installed this frame like motor, die punch, connecting rod, belt.

HEATER COIL:- Heater coil is used in this machine for heating the papers to gives desire shape, and coils are place below the die of cup and dish.

Motor:-

We are using one motor which is having 600rpm of speed. This motor is used for gives the rotation of crank shaft assembly. Motor need 1phase current supply.

Crankshaft:- the crankshaft mounting on the top of the frame and die is connecting to crankshaft with 
assembly of connecting rod. the crankshaft gives rotation which convert the reciprocating motion to the die. due to this its perform their operation, the crankshaft is commonly used in internal combustion engine

Belt:-belt is in this project to transmitting the power from electric motor to crank shaft and it's mounting on the crank pulley and motor pulley.

\section{III- APPLICATION TECHNIQUE}

\section{Drilling}

Drilling is a metal cutting process carried out by a rotating cutting tool to make circular holes is solid materials. The tool which makes holes is called as drill bit or twist drill drilling machine. Drilling machine a power operating machine tool which holds the drill in its spindle rotating at high speed and when actuated move actuated moves linearly against the work piece products a hole. Drilling has chuck capacity of 0.5 inch and no load speed is $1000 \mathrm{rpm}$ and having electric frequency $60 \mathrm{~Hz}$.

\section{WELDING:-}

welding is the process of joining together two pieces of metal so that bounding takes place at their original surface when two parts to be joined are melted together heat o pressure or both is applied and with or without added metal for formation of metallic bond.

\section{Cutting:-}

Cutting processes include sawing, milling, turning, drilling, broaching. Multi edge cutting tools are used for milling and drilling operations. It has power consumption of $2000 \mathrm{~W}$ and having speed $3800 \mathrm{rpm}$. We use saw blade diameter of $355 \mathrm{~mm}$ and bore is $25.4 \mathrm{~mm}$.

\section{GRINDING:-}

Grinder is power tool use for operation of grinding which is kind of machining using cutting tool as abrasive wheel. Small chips are cut by each grain abrasive on surface of wheel from work piece via shear deformation.

\section{IV- WORKING}

In our Electric operated paper cup making machine one phase electric motor is transmitting the rotary motion to the crank shaft with the help of belt. The crank converts the rotary motion into reciprocating.

Due to the crank punch moves downward and it exert a pressure on paper sheet, then it gain a shape of die. Heater coil which is place below to the die for removing remaining water contain and also help to easily deform our paper cup required shape to dish or cup. Now punch moves upwards and dish or cup can be remove from die. in this way the electric power operating paper cup machine works.

\section{ADVANTAGES}

- This product is an alternative for plastic cups and paper cups.

- It can easily decomposing.

- Cheaper and easily available material is used.

- Eco-friendly products.

- Simple in construction.

- Easy to maintain and repair.

- Cost of the unit is less.

- No fire hazard problem due to over loading.

- Continuous operation is possible without stopping.

- It occupies less floor space.

- Less skilled operator is sufficient.

\section{V- RESULT}

Thus the design and fabrication of electric operating paper cup machine using die and punch have been designed and the working of the machine is analyzed. The electric operating machine is better than hydraulic and pneumatic. Because, the hydraulic and pneumatic machine introducing a problem of oil and air leakages.

\section{VI- CONCLUSION}

The electric operating system is better than hydraulic and pneumatic system in terms of maintenance, cost and accuracy. The machine frame is carefully designed and cross checking where it does meet the equirements. The scope of the project was making the cost of the paper cup making machine as low as possible and increasing its efficiency.

1) Reducing of man power.

2) Eliminate the storage space. 


\section{REFERENCES}

[1] Design of Electrical Mchine -K.G. Upadyay.

[2] Design of machine element book of engineers compiled by VB BHANDARI.

[3] A Textbook Of Production Engineering Copiled By P.C. Sharma.

[4] EBook of Heating with electricity (home heating and cooling series ) issued also in French under title: Le chauffage a l'electricite ISBN 0-662-33774-3 cat. No. $m 91-2 / 119-2003 E$

[5] EBook of fundamentals of design 2008 Alexander slocum.

[6] "Design and Fabrication of ELECTRIC Operated Paper Cup Making Machine" Vignesh K Eet al ,PSNA College of Engineering \& Technology, Dindigul-624622, Tamil Nadu India

[7] Design And Fabrication Of Foot Operated Bowl Making Machine, Dr.A $K$ bha*,sayali ghogale, sushma kadm,pratiksha sawant, mechanical engineering kankali,Maharashtra,india.

[8] "Fabrication of pneumatically operated paper cup and dish making machine" Ashwini Masurkar, Rushikesh Kolape, Sneha More, Yogesh Mane, prof. Dinesh Pargunde.Department of Mechanical Engineering, Saraswati College of Engineering, Kharghar, Navi Mumbai, India. 